\title{
Application of a topographic 3D Scanner to irrigation research
}

\author{
by \\ Playán, E. ${ }^{1}$ Zapata, N. ${ }^{1}$, Burguete, J. ${ }^{1}$, Salvador,.$^{1}{ }^{1}$ and Serreta, A. ${ }^{2}$
}

\begin{abstract}
A topographic three dimensional scanner is similar to a radiometric total station, but it does not require a reflecting prism and the optical measurement device is motorized and automated. With this device, very large survey data sets can be collected with moderate effort. In this paper, the application of a 3D scanner to surface and sprinkler irrigation research is presented and discussed. In surface irrigation, the scanner was successfully applied to: 1) the survey of soil surface elevation, including furrowed areas; 2) the determination of flow cross sections; 3) surveying the location of the advancing front; and 4) measuring water surface elevation. The device showed some limitations in the measurement range, which was limited to about $35 \mathrm{~m}$ for water surface elevation and $50 \mathrm{~m}$ for the detail survey of furrowed areas. In sprinkler irrigation, the scanner was applied to the survey of the sprinkler jet and the irrigation drops during their trajectory. The scanner seemed to fail to survey fine drops, since falling drops were rarely scanned in the vicinity of the sprinkler. Despite the reported limitations, the 3D scanner seems to be destined to occupy a relevant place in the irrigation research laboratory.
\end{abstract}

\footnotetext{
${ }^{1}$ Dept. Soil and Water, Aula Dei Experimental Station, CSIC. P.O. Box 13034, 50080 Zaragoza, Spain. enrique.playan@eead.csic.es, vzapata@eead.csic.es, jburguete@eead.csic.es, rsalvador@eead.csic.es

${ }^{2}$ Escuela Politécnica Superior de Huesca, Universidad de Zaragoza. Ctra. de Cuarte, s/n, 22071. Huesca, Spain. serreta@unizar.es.
} 
Keywords: Surface irrigation, sprinkler irrigation, level-basin, border, furrow, ballistic model, hydrodynamic model, soil surface elevation, flow depth, jet trajectory, drop 


\section{Introduction}

Irrigation research requires topographic information for a variety of purposes. In drip irrigation water is applied at specific, discrete points of the soil surface. Consequently, topography is required to reveal the coordinates of singular points, such as bifurcations, control elements or points along the distribution or application pipelines. In surface and sprinkler irrigation water is applied in a continuous way in the whole field or in sections of it. Discrete points are of interest in surface and sprinkler systems, such as the coordinates of canal turnouts or the location of sprinklers and sprinkler control elements. However, the continuous nature of water application requires specific topographic attention.

In surface irrigation systems, the field slope typically is determined with optical topographical equipment, using as little as two elevation points. In the 1990s, topographical radiometric total stations automated data storage. This development made it easy to use dozens of distance-elevation pairs, and field slope was often determined through linear regression.

Radiometric stations were also used to address problems related to leveling quality in borders and particularly in level-basins. The quality of land leveling traditionally limited both the dimensions and the performance of level-basins. The introduction in the 1970s of laser-guided land leveling led to systematic analyses of the effect of microtopography on irrigation performance. The first studies qualitatively described the relationship between soil surface elevation and irrigation depth (Erie and Dedrick, 1979; Walker and Skogerboe, 1987). The availability of radiometric stations permitted to analyze the spatial variability of soil surface elevation using geostatistics and numerical simulation models (Playán et al., 1996a; Playán et al., 1996b; Clemmens et al., 2003). Hundreds of survey points were required for this task, making field data collection time consuming. In practice, the volume of elevation data was limited by the required field effort. 
In furrow irrigation, measuring the furrow cross section has always been a time-consuming task. A metal plate vertically introduced in the furrow section was used to draw the furrow section. A less invasive technique, the furrow profilometer, was used to measure the coordinates of a furrow section using vertical metal bars sliding down from the furrow crest elevation to touch the soil surface (Walker and Skogerboe, 1987). These techniques are labor-intensive, and often failed to reveal the cross sectional variability along the furrow and among furrows. Furrow erosion/deposition processes produce relevant dynamic changes in geometry along the furrow during an irrigation event (Fernández-Gomez et al., 2004; Mateos and Giráldez, 2005). Detailed measurements of furrow longitudinal slope and cross section before and after the irrigation event are required for the validation and application of numerical simulation models using the latest numerical developments in this field (Murillo et al., 2008).

The measurement of flow depth in surface irrigation has been an area of intense developments. From the initial staff gages, difficult to read with millimetric accuracy, a number of devices have been applied to surface irrigation. Clemmens et al. (2003) used controlled leak cups to measure flow depth time evolution in a network of points within a level-basin. Playán et al. (2008) used a number of electro-mechanic flow depth recorders to characterize flow depth in a series of interconnected rice paddies. All these measurement techniques need to relate the flow depth measurements to the local soil elevation. Detailed topographic surveys of the vicinity of the measurement devices are needed for this purpose. Variations in soil surface elevation during the irrigation events make it very convenient to measure soil surface elevation and water surface elevation with the same topographic equipment (using the same coordinate system), so that flow depth can be readily related to soil elevation.

Another aspect of topography applied to surface irrigation is recording the location of the advancing front in borders and particularly in level-basins. This is a major challenge in the presence of poorly leveled soil surface. Playán et al. (1996b) left markers on the soil identifying the front location at different times. 
The markers were later on surveyed with a total station. Clemmens et al. (2003) used the coordinate system created by the trees in a citrus plantation to locate the advancing front. GPS equipment can now-a-days be used to record the coordinates of points along the advancing front. These techniques still require that the observers continuously move along the field during the irrigation event.

In sprinkler irrigation, experiments have been performed to characterize water application at different distances from an isolated sprinkler or in regular networks with different sprinkler spacings. Drop diameter and velocity have been measured with different techniques (Salvador et al., 2009), in an effort to produce data sets that can be used to calibrate numerical models or to estimate water application and irrigation water kinetic energy. However, the morphology of the sprinkler jet in calm or windy conditions has not been assessed in detail. This information is valuable to progress in the predictive capacity of current simulation models and to improve the understanding of the process of jet breakup into isolated drops (Carrión et al., 2001; De Wrachien and Lorenzini, 2006; Burguete et al., 2007).

This work presents the application of the three dimensional scanner to different aspects of irrigation research. The $3 \mathrm{D}$ scanner is very similar to a radiometric total station, but it does not require a prism and the optical measurement device is motorized. Consequently, the collection of very large data sets is affordable. Applications of the 3D scanner to the survey of soil surface elevation, water surface elevation and sprinkler irrigation jets are presented and discussed. 


\section{Materials and Methods}

Radiation technologies have been used to determine distances in a wide set of applications. When these technologies are used to obtain the surface coordinates of three dimensional objects in an automated fashion, the resulting device is often referred to as a 3D scanner. There are, however, many different types of devices receiving this generic name. Some of them are based on laser, while others are based on ultrasound or radar. Applications of 3D scanners have been common in medical sciences and manufacturing engineering, using small indoor devices applying different laser techniques. In one of the few applications of this technology to hydraulics and hydrology, Peña González et al. (2007) used an active triangulation laser scanner to monitor the time evolution of a submerged obstacle subjected to erosion and deposition.

A type of laser technology relevant to 3D scanners is the LIDAR (Light Detection and Ranging). Airborne and ground technologies have been developed for different applications of this technology in the natural resources, military, meteorology and agronomy, among others (Moran et al., 2003; Fujisaki et al., 2008). Topography is an emerging field for 3D scanners, which are quickly replacing radiometric total stations in selected applications due to its prismless operation and its capacity to obtain massive data sets.

A ScanStation 3D scanner, manufactured by Leica, was used for all the experiments reported in this paper (mentioning the model and trademark does not imply endorsement). This is a pulsed, dual-axis compensated, high-speed laser scanner, with survey-grade accuracy, range and field of view. It uses a visible green laser beam, with a range of 150-300 m, depending on surface conditions. According to the manufacturer's specifications, target acquisition is characterized by a $2 \mathrm{~mm}$ standard deviation. The instrument includes a digital camera, which is used to visually determine the region to be scanned in spherical coordinates. During the scan, the instrument head automatically rotates while a mirror oscillates in the vertical direction. Both movements can be programmed to cover the selected area with the user specified vertical and 
horizontal angular steps. The angular accuracy (vertical and horizontal) is $60 \mu \mathrm{rad}$. Scanner operation is typically controlled from a computer, where job specifications are set and data are received and stored. The time required to complete a scanning job depends on the extent of the selected region and on the survey point density. Under the experimental conditions the equipment surveyed about 1,500 points $\mathrm{s}^{-1}$.

The 3D scanner output can be presented in a number of different formats. The most relevant output includes:

- Cartesian coordinates of the laser reflection point. When a laser beam finds an object it reflects, and part of the radiation reflects back to the scanner (the "backscattering" process). The radiation time of flight is used to estimate the distance from the emitter to the object. The combination of distance, vertical and horizontal angles constitute the spherical coordinates of the reflection point, which are transformed into a cartesian coordinate system. If a laser beam finds a reflecting object, its coordinates are recorded. If a reflecting object is not found (i. e., a beam aiming at the atmosphere), then no coordinates are registered for that particular pair of horizontal and vertical angles.

- Intensity. This is an expression of the ratio of the received to emitted laser intensity corresponding to each reflected point. This variable is digitally recorded, in the form of an integer spanning from $-2,047$ to $+2,048$.

- RGB values, ranging from 0 to 255 each. These variables permit to create synthetic color images of the scanned surfaces. This information was not used in the present paper.

\section{Surface irrigation experiments}

Three adjacent irrigation borders (A, B and C), each $100 \mathrm{~m}$ long and $1.6 \mathrm{~m}$ wide, were constructed on an area with zero slope (Fig. 1). The border dikes had a vertical slope of approximately 1:1. Borders A and B were irrigated from opposite ends using a discharge of $2.0 \mathrm{~L} \mathrm{~s}^{-1}$. Inflow was cut-off at the final 
advance time, 160 and $111 \mathrm{~min}$, respectively. The discharge applied to border $\mathrm{C}$ was $1.6 \mathrm{~L} \mathrm{~s}^{-1}$ and lasted $113 \mathrm{~min}$. Irrigation proceeded from left to right in borders $\mathrm{A}$ and $\mathrm{C}$ and from right to left in border $\mathrm{B}$. A nearby agrometeorological station recorded wind speed and direction at an elevation of $2.0 \mathrm{~m}$. Wind records were registered at $1 \mathrm{~min}$ intervals. Wind speed was high during both irrigation events $(A+B$ and $C)$, averaging $3.5 \mathrm{~m} \mathrm{~s}^{-1}$ and blowing in an approximate right to left direction.

The 3D scanner was used to survey the soil surface before and after the irrigation event in borders A and B. These surveys were performed at an angular increment of $3.055910^{-4} \mathrm{rad}$. This was a time consuming operation (about 10-15 min, in each case), but the operation time was not a limiting factor, since there was no water movement in the experiment. The soil survey following the irrigation events was performed days after the end of the recession phase.

The survey time was a limiting factor when the 3D scanner was used to monitor the advance phase of borders A, B and C. An angular increment of $5.324010^{-4} \mathrm{rad}$ was used in this case, leading to average survey times of $7 \mathrm{~min}$ for borders $\mathrm{A}$ and $\mathrm{B}$ and $6 \mathrm{~min}$ for border $\mathrm{C}$. The area to be scanned determines the final number of points and the time required to perform the scan. This time was too high to assign the scanned advance to a single irrigation time, since one scan lasted for 3-5\% of the total advance time. Consequently, each scan was assigned to a time interval.

The 3D scanner was stationed on the left of the borders, first between borders $\mathrm{A}$ and $\mathrm{B}$, then next to border $\mathrm{C}$. These locations permitted adequate line-of-sight of the irrigated area for all borders. The 3D scanner elevation over the soil surface averaged $1.75 \mathrm{~m}$. Since this height determines the angle of incidence of the laser beam on the soil or water surface, the angle was very small, particularly at large distances from the scanner. Consequently, point density was large in the vicinity of the scanner and small towards the right end of the field. 
In all figures relating to these experiments, coordinate $x$ represents the length along the border, with the 0 located next to the 3D scanner. Coordinate $y$ runs along the border width (left to right), and coordinate $z$ is elevation.

\section{Sprinkler irrigation experiments}

Sprinkler irrigation experiments were performed with a single sprinkler, model VYR35 (VYRSA, Burgos, Spain). The objective of the experiments was to examine the morphology of the sprinkler jet and the location of the drops in their trajectory from the jet to the soil. The 3D scanner was stationed $25 \mathrm{~m}$ from the sprinkler. Scanner experiments were conducted with the sprinkler fixed to avoid rotation. If the sprinkler is allowed to rotate, the scanned image will contain parts of different sprinkler revolutions because the sprinkler revolution time (about $30 \mathrm{~s}$ ) is only a fraction of the scanning time, which is in the order of minutes. Although rotation was not permitted, the sprinkler arm oscillated in its normal motion. This setup allows to examine the sprinkler jet in three dimensions, and to assess wind impacts on jet trajectory and shape. Burguete et al. (2007) tested the same sprinkler with operating pressures in the range of 200$500 \mathrm{kPa}$ and reported that a fixed sprinkler jet could travel 1.2-2.4 m farther than a freely rotating sprinkler jet. The authors attributed this difference to jet aerodynamics.

3D scanner measurements of the sprinkler jet were compared with photographic images. Both methods were used to determine the upper and lower jet boundaries at different distances from the sprinkler. For this experiment, sprinkler rotation was permitted. Photographs were taken with a Nikon D80 model in automatic mode (both shutter speed and diaphragm opening). The shooting mode was continuous, at an initial speed of 2.9 photographs per second. The experimental procedures faced some inherent difficulties. First, it was impossible to cover all the jet in just one photograph because the sprinkler rotation results in the jet being located in several vertical planes simultaneously. As a consequence, in plan view, the sprinkler jet is broken in several pieces located at different angles from the sprinkler. To 
address this problem, a radial reference line was marked on the soil, and the camera was stationed on a tripod located in front of this line. During the photographic session, a $2.40 \mathrm{~m}$ long ruler was placed vertically at different distances along the reference line (from $0.57 \mathrm{~m}$ up to $10.67 \mathrm{~m}$ ). When the jet approached the reference line, the continuous shot was activated. Only the photographs taken when the jet was over the line were selected. All distances in each photograph (distances to the sprinkler and upper and lower jet boundaries) were determined by reference to the ruler. The upper and lower jet trajectories were measured in each photograph every $0.20 \mathrm{~m}$ along the sprinkler radius. Sprinkler jet geometry data resulting from the photographs and the scanner were plotted together for comparison purposes. The experiment was repeated, and the jet and drops were surveyed using the $3 \mathrm{D}$ scanner. In this case the sprinkler was fixed to avoid rotation. These photographic and scan tests were conducted with a $4.8 \mathrm{~mm}$ nozzle, using an operating pressure of 200 $\mathrm{kPa}$, and under windless conditions.

Finally, experiments were performed to characterize the jet with variable drop diameters. Relatively fine drops were produced by using a $3.2 \mathrm{~mm}$ nozzle and an operating pressure of $400 \mathrm{kPa}$. Relatively coarse drops were obtained using a $4.8 \mathrm{~mm}$ nozzle and an operating pressure of $200 \mathrm{kPa}$. In this series of experiments the sprinkler and the sprinkler arm were fixed to prevent both rotation and the impact of the arm against the jet. The selected angular increment was $1.009110^{-3} \mathrm{rad}$. The scan time, derived from the density and the selection of the region of interest, ranged from 4 to $7 \mathrm{~min}$. A nearby agrometeorological station recorded wind speed and direction at an elevation of $2.0 \mathrm{~m}$ and at $1 \mathrm{~min}$ intervals. The continuous monitoring of these variables permitted to scan the sprinkler jet with different wind speeds and directions: against the wind $\left(180^{\circ}\right)$, at $90^{\circ}$ from the prevailing wind and along the wind $\left(0^{\circ}\right)$. The sprinkler was manually rotated to obtain the desired angles in each case. The average wind speed during the experiments was as follows: in the $3.2 \mathrm{~mm} / 400 \mathrm{kPa}$ experiments, average wind speeds were 1.8, 2.3 and $3.3 \mathrm{~m} \mathrm{~s}^{-1}$ for directions against, $90^{\circ}$ and along the wind, respectively; in the 
$4.8 \mathrm{~mm} / 200 \mathrm{kPa}$ experiments, average wind speeds were 2.3, 2.5 and $3.3 \mathrm{~m} \mathrm{~s}^{-1}$ for directions against, $90^{\circ}$ and along the wind, respectively. 


\section{Results and discussion}

\section{Surface irrigation field elevation characterization}

Soil surface elevations before, during and after the irrigation of border A at distances from the inlet between 10 and $11 \mathrm{~m}$ are presented in Figure 2 using elevation contour maps and shaded reliefs. The plots in Fig. 2 present a very detailed representation of soil surface elevation at the border bottom and at the dikes. The contour maps show that most of the flat region is in a $0.03 \mathrm{~m}$ interval. This situation continues after irrigation, with part of the central area (showing a wheel track) depressing more than the rest of the border. The shaded relief plots permit to appreciate the small scale soil surface irregularities. After irrigation, these irregularities present ripple mark patterns, evidencing the effect of erosion/deposition processes.

The local density of scanned points before the irrigation event was 4,443 points $\mathrm{m}^{-2}$. This density exponentially decreased with distance to the 3D scanner, presenting values of 133 points $\mathrm{m}^{-2}$ at a distance of $50-51 \mathrm{~m}$ and 29 points $\mathrm{m}^{-2}$ at a distance of 90-91 m. Consequently, soil surface elevation maps could not be produced at distances of $50 \mathrm{~m}$ and beyond. Point densities at these locations were not sufficient for adequate two-dimensional characterization of the border dike topography.

Even at the lowest reported point density the scanner represents a major advantage over radiometric total stations. In a detail research analysis of leveling quality in a small experimental level-basin, Playán et al. (1996a) used a survey density of 0.42 points $\mathrm{m}^{-2}$. Analyzing typically sized level-basins, Playán et al. (1996b) reported survey densities of 0.034-0.052 points $\mathrm{m}^{-2}$. The manual, time consuming operations of moving the prism to the target points, aiming at the prism and recording data make total radiometric stations an unsuited technology for detailed surface irrigation survey studies. The reported 3D scanner point density is more than sufficient to characterize the bottom of a level basin or a border. Survey data could be readily used to feed twodimensional models of basin and border irrigation. The resulting simulation 
detail would be much higher than that reported by Playán et al. (1996b) or Clemmens et al. (2003). This is particularly important since microtopography can be the most relevant source of non-uniformity in border and particularly in level-basin irrigation (Zapata et al., 2000).

Elevation data produced by the 3D scanner were sufficient to characterize the variation in border cross section with distance (Figure 3). The Figure presents the cross section at three distances, obtained by a $y$ vs. $z$ scatter plot of all survey points located in a $1 \mathrm{~m}$ border length interval. The cross sections can be obtained even at long distances from the scanner. This technique can also be used to characterize furrow cross sections and elevations for distances of at least $100 \mathrm{~m}$ with the reported scanner point density. Detailed furrow longitudinal profiles and cross sections are needed when modeling erosion/deposition, the turbulent mixing of water and fertilizers, and furrow irrigation networks (levelfurrow systems). As an example, Burguete et al. (2009) reported major difficulties when analyzing furrow confluences/bifurcations due to the limited spatial topographic detail derived with radiometric total stations. The analysis of furrow elevation profiles and sections before and after an irrigation event would be particularly useful to validate such models.

The lessons learned from this experiment apply to different types of surface irrigation systems. If the 3D scanner is used to characterize furrow geometry, a detailed data set will only be obtained in the vicinity of the scanner (less than 50 $\mathrm{m})$. For long furrows, the 3D scanner will have to be stationed at different locations along the furrow. If the scanner is stationed in the middle of a furrow, it can survey furrow regions upstream and downstream from the station point. Detailed surveys would be justified for applications such as the quantification of erosion/deposition in different furrow sections, or the validation of nonhydrostatic furrow simulation models (Bradford and Katopodes, 1998), which can be very affected by differences in soil elevation. If only furrow section geometries are required at different distances along a furrow, the 3D scanner can produce excellent results with moderate effort. The reported results indicate that reasonable average sections can be obtained at distances of up to $100 \mathrm{~m}$ 
(this makes $200 \mathrm{~m}$ span if the scanner is stationed in the middle of a furrow). In any case, in normal operating conditions the 3D scanner could probably survey three adjacent furrows simultaneously without relevant shadow areas. If the 3D scanner is used to characterize border/basin bed geometries, it can be stationed in the center of the field and produce a $360^{\circ}$ radiation to scan the soil surface at a survey point density that would be unaffordable with any other currently available topographic device. The typical operational range of $150-300 \mathrm{~m}$ is sufficient for the vast majority of borders and basins.

\section{Surface irrigation flow characterization}

The 3D scanner can be used to locate the advancing front and determine flow depths based on its ability to distinguish the soil surface from the water surface.

Figure 4 presents survey points obtained in borders A and B (and the soil strip separating them) at three distance increments $\delta x(8-10,40-42$ and 90-92 $\mathrm{m})$ and at two irrigation time intervals $\delta \mathrm{t}$ (3-10 and 51-58 min). At each time and distance intervals, one of the borders (shaded in grey) was covered with irrigation water.

At distance 8-10 m, border A was partially covered by water (mostly the region along $y=5$ ). Comparison of both borders at this time interval shows that the presence of a free water surface on the soil diminishes the chance of the laser beam to reflect back to the scanner. The region covered by water has a smooth surface, and produced in the Figure vertically aligned points (in fact, sections of circumferences). In the region not covered by water, the location of survey points denotes the differences in elevation. As a consequence, points accumulate at slopes facing the 3D scanner; shadow areas (without points) appear at the slopes facing the other direction.

At $\delta x=40-42 \mathrm{~m}$, the density of survey points resulted much lower, as previously discussed. Only a few survey points were obtained in the border covered by water (border A). Some of the points surveyed in border A could actually correspond to high spots, uncovered by water. The density of points obtained in border B was uniform throughout the region. 
At the furthest region $(\delta x=90-92 \mathrm{~m})$, very few survey points were obtained in both cases, with the difference between soil and water not being as clear as at the other distances.

Survey points were more difficult to obtain from free water surfaces than from the soil surface, especially at large distances from the scanner because of the effect of distance on scanning density. This problem is believed to be more the result of the angle of incidence than of distance itself. We hypothesize that the water surface mostly reflects the laser beam, while backscattering is needed to register a survey point. This is more likely to happen when the angle of laser incidence is close to horizontal.

The location of the advancing front was determined using the laser intensity provided by the 3D scanner for each survey point. Figure 5 presents contour maps of laser intensity for borders A and B at different time intervals. The soil and water surfaces can be clearly distinguished in the left half of the Figure $(x<50 \mathrm{~m})$, but not in the right part of the Figure $(x>50 \mathrm{~m})$. Hence, locating the advancing front is difficult for distances greater than $50 \mathrm{~m}$. Figure 6 presents a detail of border A, including the advancing front. Both the laser intensity (in a contour map) and the surface elevation (in shaded relief) are presented. The free water surface corresponds to the flat in the shaded relief plot and to negative values in the laser intensity plot. Laser intensity can be used as a quick, accurate way to indicate irrigation advance in the vicinity of the scanner. Image analysis software could be readily used to map advance and estimate the area covered by water.

Water surface scans can be combined with soil surface scans before and after the irrigation event to determine flow levels (and their space and time variability) and overland water volumes. Unfortunately, these measurements require a large number of survey points and are limited to distances no greater than $50 \mathrm{~m}$ away from the scanner.

Figure 7 presents scanned elevations with distance along border C, before irrigation and at three time intervals during irrigation. The data are for a $1 \mathrm{~m}$ 
wide strip located in the center of the border and are presented up to a distance of $45 \mathrm{~m}$, where water surface survey points become scarce. Soil surface elevation data present a very large variability and relevant undulations along the border. The elevation data obtained during irrigation advance result in the low spots of the border being replaced by water elevation points. Water points are very consistent in elevation, with most of the survey points being located in a $0.5 \mathrm{~cm}$ elevation interval. Considering the strong winds present during the irrigation event, most of this variability in water surface elevation could correspond to wind-induced waves. The subplots corresponding to different times show that water level increases with time, while the water surface becomes more horizontal. In the Figure, the vertically aligned survey points, correspond to survey stakes located at $5 \mathrm{~m}$ intervals. Note, however that the scanner generated points above and below the water surface. We attribute these results again to the reflection of the laser beam on the water surface. A reflected laser beam gains elevation and distance to the scanner. In its new trajectory, it hits one of the stakes and backscatters from it. If the radiation reaches the 3D scanner, the distance water - soil surface - stake is assigned to the original angle of the beam. Consequently, the 3D scanner interprets that this point is located below the water surface. In the analysis of border $C$, it is clear that valid water surface points could only be obtained at a distance up to $35 \mathrm{~m}$ from the scanner. Application of the 3D scanner to surface irrigation evaluation will face problems related to the distance separating the scanner and the target. In the experimental conditions of this paper, the determination of the location of the advancing front and flow depth are both possible and accurate for distances up to $35-50 \mathrm{~m}$. This range can be adequately exploited to evaluate furrows up to 70$100 \mathrm{~m}$ long, and between $70 \times 70 \mathrm{~m}^{2}$ and $100 \times 100 \mathrm{~m}^{2}$ basins and borders. $\mathrm{In}$ situations different than this, particular arrangements will have to be made, including multiple 3D scanner station points. Simultaneous use of several scanners for evaluation purposes will be limited by the cost of the device, which currently is about one order of magnitude higher than that of a radiometric total station. One final consideration on the accuracy of flow depth 
measurements in open field conditions is the effect of wind speed. While some of the flow depth measurement methods reported in the literature require stilling basins, the 3D scanner directly measures flow depth on the field. As a consequence, wind-induced waves may create measurable oscillations. This seems to be the case of the experiment reported in this paper, although the variability in measured elevation was less than $10^{-2} \mathrm{~m}$ in all cases.

\section{Sprinkler irrigation jet trajectory and morphology}

Figure 8 presents the VYR35 jet trajectory measured with the 3D scanner and photographs. The sprinkler jet showed an asymmetrical parabolic shape. Scanner and photograph data for the first meter of the jet were used to measure the jet angle $\left(25.9^{\circ}\right)$, which was similar to the value reported by the nozzle manufacturer $\left(26^{\circ}\right)$. The upper jet boundary could be observed much more accurately than the lower boundary from the photographic data. At the lower boundary the jet limit was often confused with the drops starting to fall out of it. The highest jet elevation was observed at a distance of $7.0 \mathrm{~m}$. At this point, the jet reached an elevation of $2.39 \mathrm{~m}$ above the nozzle. The vertical jet width increased with distance to the sprinkler. Experimental difficulties in the observation of the lower boundary made it difficult to estimate jet width.

Data from the 3D scanner were mostly in agreement with the photographic data. Agreement was very good for the upper jet trajectory points. The scanner measured relatively few drops at $0-4 \mathrm{~m}$ from the sprinkler; this suggests that the scanner identifies drops within the upper part of the drop diameter range. In fact, very few drops were scanned at proximal distances (0-2 $\mathrm{m})$, where drop diameters are typically below $1 \mathrm{~mm}$ (Salvador et al., 2009). Drop density therefore increases with distance to the nozzle, up to the maximum flight distance of $14.0 \mathrm{~m}$. Most of the scanned drops in the distance range of 2-6 m could be tentatively attributed to the effect of the sprinkler impact arm, which was observed to produce larger drops falling in that area. Part of the small differences between the 3D scanner and the photographs can be attributed to 
the use of a rotating sprinkler when photographs were taken and a fixed one when the scanner was in operation.

Figures 9 and 10 present a detailed analysis of the sprinkler jet and drops resulting from fixed sprinklers with the impact arm disabled under varying wind exposure conditions. The experimental setup favored the formation of fine drops in Figure 9 and coarse drops in Figure 10. In the first column of plots $(\mathrm{a}, \mathrm{b}$ and $\mathrm{c})$, the wind direction is at $180^{\circ}$ from the sprinkler direction; in the second column $(\mathrm{d}$, e and $\mathrm{f})$ the wind direction is $90^{\circ}$; and in the third column $(\mathrm{g}$, $\mathrm{h}$ and $\mathrm{i}$ ) it is $0^{\circ}$. The three dimensional plots illustrate the nature of the jet in each case, although detailed analyses are provided in vertical plane (b, e and $h$ ) and plan view plots ( $c$, $\mathrm{f}$ and $\mathrm{i}$ ). Vertical plane plots were obtained plotting the horizontal distance from the drop to the sprinkler vs. drop elevation. These plots illustrate the effect of the wind direction on sprinkler jet trajectory and morphology. In Figure 9 (plots b, e and h), the sprinkler jet reaches about 5, 8 and $15 \mathrm{~m}$ when the wind direction is at $180^{\circ}, 90^{\circ}$ and $0^{\circ}$ relative to the sprinkler jet direction, respectively. In Fig. 9b, the wind takes a large part of the irrigation water, which seems to be incorporated into the air stream. Short periods of high wind speed seem to cause the accumulation of drops in certain regions of Figs. $9 \mathrm{~g}$ and $10 \mathrm{~g}$. The importance of this short-time variability in wind speed is much clearer in the plan views, which show zig-zag patterns. The data presented in these two figures is very relevant to the improvement of sprinkler irrigation ballistic models. Specific experiments will have to be performed to confirm that drops are detected by the 3D scanner depending on their diameter, as suggested by Fig. 8 and subfigures $9 \mathrm{e}, 9 \mathrm{~h}, 10 \mathrm{e}$ and $10 \mathrm{~h}$. If this is the case, the minimum diameter for scanner detection will have to be determined. Finally, ballistic models will have to be reformulated to reproduce the observed jet morphologies, particularly in the presence of wind. These studies will contribute to the development of more physically based simulation models. 


\section{Conclusions}

A 3D scanner has been evaluated for use in irrigation research. The application of the device seems very promising for surface and sprinkler irrigation evaluation and simulation. Limitations have been found in the measurement range, which apply to surface irrigation. In sprinkler irrigation, however, the measurement range seems to be adequate for the tested applications. The 3D scanner has proved to be a very important tool for irrigation research, producing data of unmatched quality. In surface irrigation, the availability of this device will permit to gather high quality data for 2D basin and border simulation, for the analysis of erosion and fertigation in furrow irrigation, and for the modeling of flow routing in level furrow networks. In sprinkler irrigation, new research objectives have been unveiled, since the scanner provides a new approach to the development and validation of ballistic simulation models. 3D scanners are currently the subject of intense technology development efforts. The reported limitations in 3D scanner measurement range and poor backscattering in the presence of a free water source will probably be solved by technical developments. According to the features of the 3D scanner reported in this paper, it can be concluded that this device will soon be a common and necessary tool in irrigation research.

\section{Acknowledgements}

This research was funded by the Plan Nacional de I+D+i of the Government of Spain, through grant AGL2007-66716-C03. We appreciate the cooperation of the surveying company "Scanner Patrimonio e Industria". The order of authors in the paper follows the "first-last-author-emphasis" criterion. 


\section{References}

Bradford SF and Katopodes ND (1998) Nonhydrostatic model for surface irrigation. Journal of irrigation and drainage engineering, ASCE, 124(4), 200212.

Burguete J, Playán E, Montero J and Zapata N (2007) Improving drop size and velocity estimates of an optical disdrometer: Implications for sprinkler irrigation simulation. Transactions of the ASABE, 50(6), 2103-2116.

Burguete J, Zapata N, García-Navarro P, Maïkaka M, Playán E and Murillo J (2009) Fertigation in furrows and level furrow systems II: field experiments, model calibration and practical applications. Journal of irrigation and drainage engineering, ASCE, 135 (4): 413-420.

Carrión P, Tarjuelo JM and Montero J, (2001) SIRIAS: a simulation model for sprinkler irrigation: I. Description of the model. Irrigation Science, 2001(20), $73-84$.

Clemmens AJ, Strelkoff TS and Playán E (2003) Field verification of twodimensional surface irrigation model. Journal of Irrigation and Drainage Engineering, ASCE, 129(6), 402-411.

De Wrachien D and Lorenzini G (2006) Modelling jet flow and losses in sprinkler irrigation: Overview and perspective of a new approach. Biosystems engineering, 94(2), 297-309.

Erie LJ and Dedrick AR (1979) Level basin irrigation: A method for conserving water and labor. USDA Farmers' Bulletin, number 2261, 23 pp.

Fernández-Gomez R, Mateos L and Giráldez JV (2004) Furrow irrigation erosion and management. Irrigation Science, 23(3), 123-131.

Fujisaki I, Evans DL, Moorbead RJ, Irby DW, Mohammadi-Aragh MJ, Roberts SD and Gerard PD (2008) Stand assessment through lidar-based forest visualization using immersive virtual environment technology. Forest Science, 54(1), 1-7.

Mateos L and Giráldez JV (2005) Suspended load and bed load in irrigation furrows. Catena, 64(2-3), 232-246. 
Moran S, Fitzgerald G, Rango A, Walthall C, Barnes E, Bausch W, Clarke T, Daughtry C, Everitt J, Escobar D, Hatfield J, Havstad K, Jackson T, Kitchen N, Kustas W, McGuire M, Pinter P, Sudduth K, Schepers J, Schmugge T, Starks P and Upchurch D (2003) Sensor development and radiometric correction for agricultural applications. Photogrammetric Engineering and Remote Sensing, 69(6), 705-718.

Murillo J, García-Navarro P, Brufau P and Burguete J (2008) 2D modelling of erosion/deposition processes with suspended load using upwind finite volumes. Journal of Hydraulic Research, 46(1), 99-112.

Peña Gonzalez E, Sánchez-Tembleque Diaz-Pache F, Peña Mosquera L and Puertas Agudo J (2007) Bidimensional measurement of an underwater sediment surface using a 3D-Scanner. Optics and Laser Technology, 39(3), 481-489.

Playán E, Faci JM and Serreta A (1996a) Characterizing microtopographical effects on level-basin irrigation performance. Agricultural Water Management, 29, 129-145.

Playán E, Faci JM and Serreta A (1996b) Modeling microtopography in basin irrigation. Journal of Irrigation and Drainage Engineering, ASCE, 122(6), 339347.

Playán E, Pérez-Coveta O, Martínez-Cob A, Herrero J, García-Navarro P, Latorre B, Brufau P, and Garcés J (2008) Overland water and salt flows in a set of rice paddies. Agricultural Water Management, 95(6), 645-658.

Salvador R, Bautista-Capetillo C, Burguete J, Zapata N, Serreta A and Playán E, (2009) A photographic method for drop characterization in agricultural sprinklers. Irrig. Sci., 27:307-317.

Walker WR and Skogerboe GV (1987) Surface irrigation. Theory and practice, Prentice-Hall, Inc., Englewood Cliffs, New Jersey.

Zapata N and Playán E (2000) Simulating elevation and infiltration in levelbasin irrigation. Journal of Irrigation and Drainage Engineering, ASCE, 126(2), 78-84. 


\section{List of figures}

Figure 1. Schematic plan view of the surface irrigation experiments. The three borders were irrigated from the left or right ends with different discharges. The arrows indicate the location of the inflow point in each border.

Figure 2. Surface elevation before, during and after the irrigation event at a distance from the inlet of 10-11 $m$ for border A. Data during the irrigation event correspond to the time interval 156-161 min. Results are presented as contour maps and shaded reliefs.

.Figure 3. Border A cross sectional geometry at distances 9-10, 49-50 and 89-90 m. Sections were obtained from soil surface elevation before irrigation. Geometries were obtained by $y$ vs. $z$ scatter plots for all points in the regions delimited by the abovementioned distances to the inlet and y coordinates between 4.2 and $6.6 \mathrm{~m}$.

Figure 4. Density of observed points at different distances from the inlet of border $A$. Results are presented for three regions including sections of borders $A$ and $B$ during irrigation time intervals 3-10 min (distance 8-10 m) and 51-58 min (distances 40-42 $m$ and 90-92 $m$ ) The grey shading indicates the border stretches which were covered by irrigation water.

Figure 5. Shaded contour maps of laser intensity for borders $A$ and $B$ at irrigation time intervals a) 3-10 min; b) 51-58 min; c) 95-102 min, and d) 156-161 min.

Figure 6. Location of the advancing front at border A during time interval 3-10 min. Results are presented as a contour map of laser intensity and a shaded relief of surface elevation.

Figure 7. Scatter plot of distance along border C vs. soil surface before irrigation and surface elevation in a $1 \mathrm{~m}$ wide central border strip. The surface elevation plots correspond to time intervals a) 24-31 min; b) 57-63 min; and c) 90-96 min.

Figure 8. Analysis of a VYR35 impact sprinkler equipped with a $4.8 \mathrm{~mm}$ nozzle operated at $200 \mathrm{kPa}$. The plot presents the drops identified by the 3D scanner (dots) and the upper and lower trajectory points obtained using photography (symbols) The sprinkler was fixed during scanning and rotated when photographs were taken. The horizontal line located at an elevation of $2.13 \mathrm{~m}$ below the nozzle represents the soil surface. Vertical lines indicate the photography observation points. 
Figure 9. Plots of the drops identified by the 3D scanner during irrigation with a fixed VYR35 sprinkler equipped with a $3.2 \mathrm{~mm}$ nozzle and operated at a pressure of $400 \mathrm{kPa}$. Plots were obtained when the sprinkler operated against the wind $(a, b, c)$, at $90^{\circ}(d, e, f)$, and along the wind $(g, h, i)$ The plot types are three dimensional $(a, d$, $g)$, drop-sprinkler horizontal distance vs. drop elevation $(b, e, h)$, and plan view $(c, f$, i)

Figure 10. Plots of the drops identified by the 3D scanner during irrigation with a fixed VYR35 sprinkler equipped with a $4.8 \mathrm{~mm}$ nozzle and operated at a pressure of $200 \mathrm{kPa}$. Plots were obtained when the sprinkler operated against the wind $(a, b, c)$, at $90^{\circ}(d, e, f)$, and along the wind $(g, h, i)$ The plot types are three dimensional $(a, d$, $g)$, drop-sprinkler horizontal distance vs. drop elevation $(b, e, h)$, and plan view $(c, f$, i) 